\title{
Génétique moléculaire des syndromes d'insensibilité aux androgènes
}

Près de la moitié des syndromes de féminisation des organes génitaux externes chez l'homme est due à une insensibilité aux androgènes, complète (donnant alors un phénotype féminin) ou partielle (engendrant une ambiguïté sexuelle). Ces affections sont dues à des altérations du gène codant pour le récepteur des androgènes, localisé en position centromérique sur le bras long du chromosome $X$ et codant pour un membre de la superfamille des récepteurs nucléaires. Les délétions semblent exceptionnelles, les mutations identifiées à ce jour étant le plus souvent ponctuelles ; l'amplification par PCR, l'électrophorèse en gradient de dénaturation, le polymorphisme conformationnel des simples brins d'ADN, le séquençage nucléotidique permettent ainsi une caractérisation rapide des lésions génétiques à la base des syndromes d'insensibilité aux androgènes.

\section{Charles Sultan Jean-Marc Lobaccaro}

\section{ADRESSES}

Ch. Sultan $(1,2)$ : professeur des universités, praticien hospitalier. J.-M. Lobaccaro(1) : étudiant en thèse.

(1) Biochimie endocrinienne du développement et de la reproduction, CHU Lapeyronie et Inserm U. 58, Montpellier, France. (2) Consultations d'endocrinologie et gynécologie pédiatriques, service de pédiatrie I, CHU Saint-Charles, 34059 Montpellier, France. es syndromes de résistance (ou d'insensibilité) aux androgènes représentent, selon les équipes, 30 à $50 \%$ des cas de pseudohermaphrodisme masculin [1] ; la clinique permet habituellement de distinguer, à côté des déficits en $5 \alpha$ réductase, les insensibilités complètes aux androgènes (ICA) (ex-testicule féminisant, phénotype complètement féminin) des insensibilités partielles aux androgènes (IPA) (phénotype ambigu). Ces deux formes cliniques se caractérisent également par une augmentation simultanée de la testostérone et de la LH (luteinizing hormone), à l'état de base et lors des épreuves dynamiques. Il y a quelques années, les travaux du groupe de C. $\mathrm{J}$. Migeon ont fourni une base bio- chimique à ces anomalies de l'action cellulaire des androgènes en évaluant la " concentration en récepteur des androgènes " de cellules cibles : les fibroblastes cutanés des organes génitaux externes. Depuis, plusieurs études ont démontré l'existence d'une hétérogénéité biochimique et génétique de ces syndromes de résistance aux androgènes : des anomalies quantitatives (diminution plus ou moins importante du nombre de sites récepteurs) ou qualitatives du récepteur des androgènes ( $R A$ ) (altérations des propriétés physico-chimiques) peuvent en effet être observées dans les formes d'insensibilité complètes et incomplètes aux androgènes [2, 3]. La disponibilité récente d'anticorps spécifiques du récepteur des androgènes va pouvoir permettre, dans un 


\section{RÉFÉRENCES}

1. Chaussain JL, Roger M, Couprie C, Sultan Ch, Job JC. Les pseudohermaphrodismes masculins. Pédiatrie 1990 ; 455: 65-72.

2. Hughes IA, Evans BAJ. The fibroblast as a model for androgen resistant states. Clin Endocrinol $1988 ; 28$ : 565-79.

3. Sultan Ch. Le récepteur cutané des androgènes : de la physiologie à la pathologie. In : Chaussain JL, Roger M, eds. Les Ambiguités sexuelles. Paris : SEPE, 1988 : 41-60

4. Van Larr JH, Bolt De Vries J, Voorhost-Ogink MM, Brinkmann AO. The human androgen receptor is a $110 \mathrm{kDa}$ protein. Mol Cell Endocrinol 1989 ; 63 : 39-44.

5. Chan L, Johnson MP, Tindall DJ. Steroid Hormone Action. In: Collu $R$, Ducharme JR, Guyda HJ, eds. Pediatric Endocrinology, 2nd ed. New York : Raven Press Ltd, 1989 : 81-124.

6. Govindan MV. Specific region in hormone binding domain is essential for hormone binding and trans-activation by human androgen receptor. Mol Endocrinol $1990 ; 4: 417-27$.

7. Van Laar JH, Bolt De Vries J, Zegzers ND, Trapman J, Brinkmann AO. Androgen receptor heterogeneity and phosphorylation in human LNCaP cells. Biochem Biophys Res Commun 1990 ; 166 : 193-200.

8. Meyer WJ, Migeon BR, Migeon CJ Locus on human chromosome for dihydrotestosterone receptor and androgen insensitivity. Proc Nall Acad Sci USA 1975; 72 : 1469-72

9. Brown CJ, Goss SJ, Lubhan DB, et al. Androgen receptor locus on the human $\mathrm{X}$ chromosome: Regional localization to $\mathrm{Xq11-12}$ and description of a DNA polymorphism. Am J Hum Genet 1989; 44: 264-9.

10. Brown TR, Migeon CJ. Androgen receptors in normal and abnormal male sexual differentiation. In : Chrousos GP Loriaux DL, Lipsett MB, eds. Steroid hormone resistance: mechanisms and clinical aspects. New York: Plenum Press, 1986 : 227-56.

11. Malpuech G, Sultan Ch, Bertheas MF, Loire C, Vanlieferingen P. Male pseudo hermaphroditism, partial androgen receptor deficit, $11 \mathrm{p} 13$ deletion : indication of gene localization. Am J Med Genet 1986; 24 : 679-84.

12. Turleau C, Niaudet $\mathrm{P}$, Sultan $\mathrm{Ch}$, Rault G, Fekete CN, De Grouchy J, Iris L. Partial androgen receptor deficiency and mixed gonadal dysgenesis in Drash syndrome. Hum Genet 1987 ; 75 : 81-3.

13. Chang G, Kokontis J, Liao S. Molecular cloning of human and rat cDNA encoding androgen receptors. Science 1988 ; avenir très proche, de réaliser le dosage de la " concentration en protéine réceptrice ".

Le clonage de l'ADNc codant pour le gène du récepteur des androgènes et la disponibilité de sondes nucléotidiques qui en découle fournissent des outils potentiellement performants pour l'analyse moléculaire des syndromes de résistance aux androgènes: recherche d'une délétion totale ou partielle du gène. De plus, la méthode d'amplification enzymatique in vitro (polymerase chain reaction, PCR) et l'étude de la séquence du gène ont mis en évidence des: mutations ponctuelles responsables du défaut d'expression du récepteur dans la cellule cible.

\section{Bases moléculaires de l'action des androgènes}

La reconnaissance du signal hormonal est une interaction physico- chimique spécifique, réversible, de haute affinité et saturable. Les principales caractéristiques du récepteur des androgènes ont été récemment rapportées [3]. Rappelons que le récepteur des androgènes (RA) est une protéine dont l'analyse par électrophorèse en gel de polyacrylamideSDS révèle une masse moléculaire de $110 \mathrm{kDa}$ [4]. Après ultracentrifugation en gradient de saccharose, le complexe androgène-RA présente un " pic " de $4 \mathrm{~S}$ à forte concentration ionique, correspondant à la forme activée [5].

Govindan a isolé deux formes différentes de récepteur des androgènes [6]. La forme A présente une séquence identique à celle trouvée par les autres groupes, tandis que la forme $\mathrm{B}$ différerait en acides aminés et lierait moins facilement les androgènes $\left(\mathrm{Kd}=10^{-8} \mathrm{M}\right)$. De plus, contrairement à la forme $\mathrm{A}$, la forme $B$ ne transactive pas une construction dans laquelle le gène rapporteur $C A T$

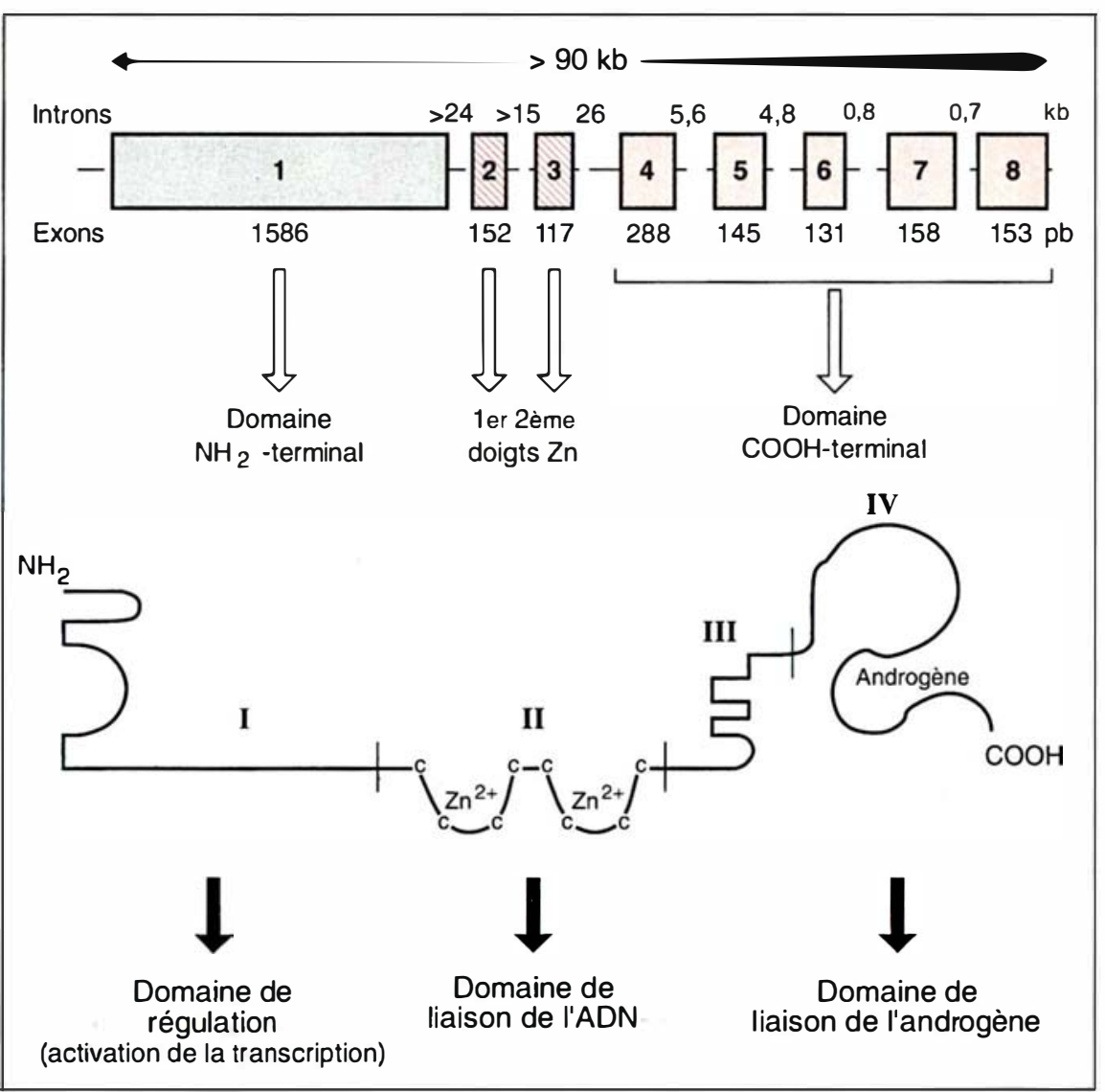

Figure 1. Organisation génétique du récepteur des androgènes humain. La taille des introns est indiquée en kilobases $(k b)$; la taille des exons en paires de bases (pb). Structure du récepteur des androgènes. 
est mis sous le contrôle des séquences régulatrices du virus MMTV (mouse mammary tumour virus) et ne se lie pas spécifiquement aux GRE (glucocorticoid response elements). Dans la lignée cellulaire $\mathrm{LNCaP}$, le groupe de Brinkmann confirme l'existence d'une hétérogénéité du récepteur des androgènes : deux bandes proches de $110 \mathrm{kDa}$ sont observées par électrophorèse sur gel de polyacrylamideSDS [7].

Le gène du récepteur des androgènes

On sait que le locus du récepteur des androgènes, localisé dans la région centromérique du chromosome $\mathrm{X}$ [8], est situé dans la région $\mathrm{Xq11- \textrm {Xq } 1 2}$ [9]. Les syndromes de résistance aux androgènes sont donc des maladies héréditaires récessives liées à l'X. L'existence de modèles animaux de "féminisation testiculaire ", où un locus Tfm sur le chromosome $\mathrm{X}$ a été décrit, a ouvert la voie à la mise en évidence, chez l'homme, du contrôle génétique des récepteurs des androgènes par le chromosome $\mathrm{X}$ [8]. L'existence d'une hétérogénéité clinique, génétique et biochimique des syndromes d'insensibilité aux androgènes a été suspectée il y a quelques années: les anomalies quantitatives ou qualitatives du récepteur des androgènes résulteraient de mutations alléliques du gène de structure codant pour le récepteur des androgènes [10] ou encore de mutations d'autres gènes (de régulation ?) sur l'X ou sur des autosomes [11, 12].

Grâce au clonage du gène du récepteur des androgènes [13-15], la structure complète du récepteur a été définie [16]. Le schéma général de la structure de ce récepteur nucléaire permet de distinguer plusieurs régions (ou domaines) et l'identification du rôle de ces différentes régions a été facilitée par des expériences de mutagenèse [17].

On reconnaît ainsi (figure 1): (1) le domaine N-terminal composé de 556 acides aminés, présentant le moins d'homologie avec les autres récepteurs nucléaires. Il est responsable de l'activation de la transcription des gènes hormono-dépendants. Cette région est caractérisée par de longs enchaînements répétitifs d'acides aminés $(27 \mathrm{Gly}, 20 \mathrm{Gln}$, $m / s n^{\circ} 7$, vol. 7, septembre 91

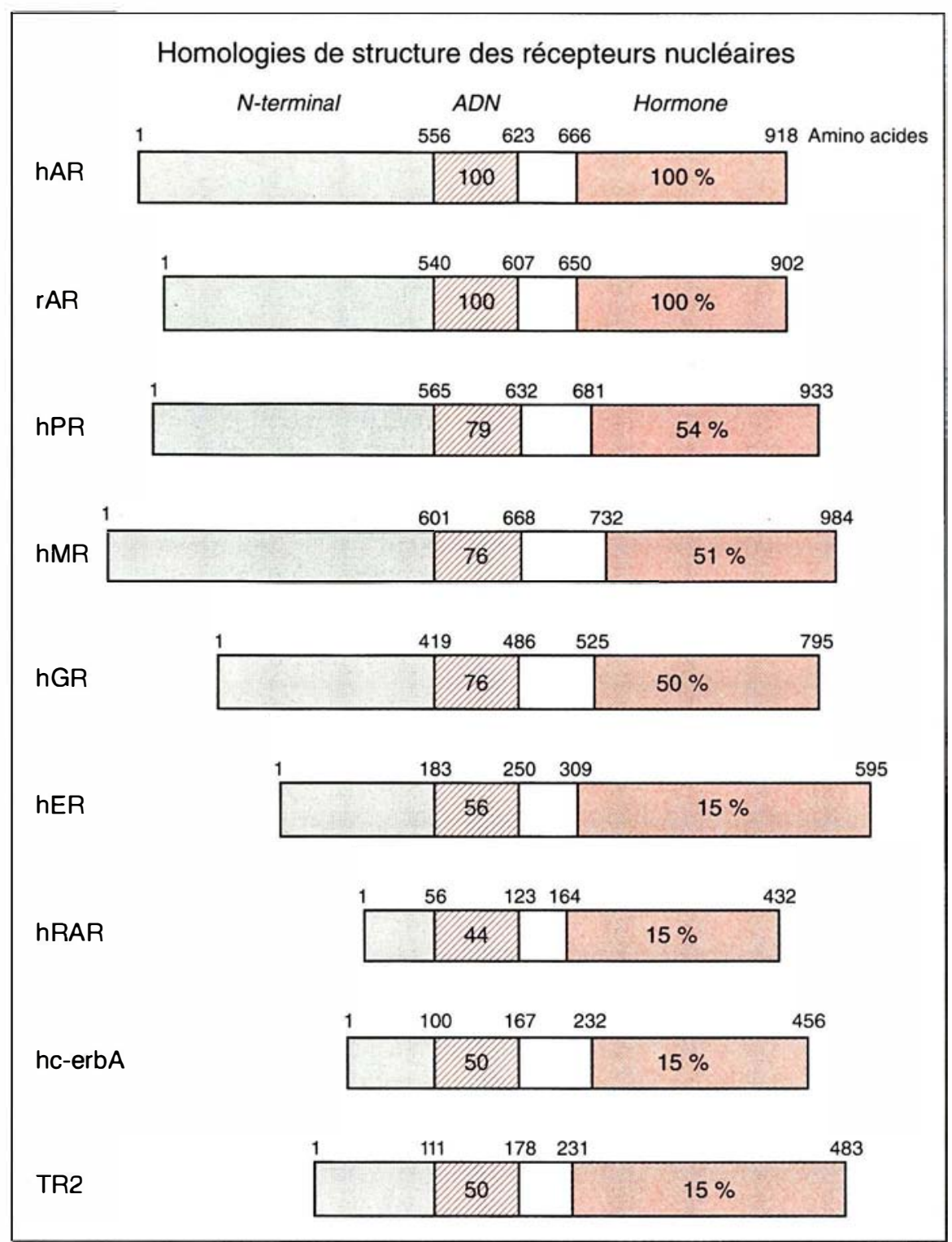

Figure 2. Structure linéaire des récepteurs nucléaires. Homologie de structure des autres récepteurs nucléaires avec le récepteur des androgènes (RA) humain pour les deux domaines de liaison à l'ADN (VIlA) et de liaison de I'hormone ( progestérone; $h G R=R$-glucocorticoïdes; $h M R=R$-minéralocorticoïdes; $h E R=R$-estrogènes $; h R A R=R$-acide rétinoïque $;$ hc-erb $A=$ oncogène $c$ erb $A ; T R 2=R$-hormones thyroidiennes.

8 Pro...). Elle porterait également le signal de transfert nucléaire; (2) 67 acides aminés ; le domaine le mieux conservé entre les différents récepteurs et les différentes espèces (homologie avec le facteur transcriptionnel TFIIIA de Xenopus lavis!). C'est un domaine riche en cystéine, chélateur de $\mathrm{Zn} 2+$ avec une structure en doigt (deux doigts). Cette région est impliquée dans la reconnaissance des HRE (hormone response elements), séquences d'ADN qui se comportent comme des amplificateurs de la transcription des gènes hormono-dépendants. Pour le récepteur des estrogènes, le premier doigt, proche de la région $\mathrm{N}$-terminale, reconnaîtrait spécifiquement le site ERE (estrogen response element), le second doigt intervenant pour stabiliser cette liaison. La reconnaissance du HRE par ce récepteur pourrait entraîner une libération ou un dépla- 


\section{RÉFÉRENCES}

14. Lubhan DB, Joseph DR, Sar M, et al. The human androgen receptor: complementary deoxyribonucleic acid cloning, sequence analysis and gene expression in prostate. Mol Endocrinol 1988; 1265-75.

15. Trapman J, Klaassen P, Kuiper GGJM, et al. Cloning, structure, and expression of a cDNA encoding the human androgen receptor. Biochem Biophys Res Commun $1988 ; 153$ : 241-8.

16. Kuiper GGJM, Faber PW, Van Rooij HCJ, et al. Structural organization of the human androgen receptor gene. $J \mathrm{Mol}$ Endocrinol 1989 ; 2 : R1-4.

17. Evans RM, The steroid and thyroid hormone receptor superfamily. Science 1988 ; $240: 889-95$

18. Baulieu EE. Récepteurs des hormones stéroïdes et oncogènes. In : Netler $\mathrm{A}$, ed. Actualités gynécologiques. Paris: Masson, 1991: 19-22.

19. Tan JA, Joseph DR, Quarmby VE, et al. The rat androgen receptor: primary structure, autoregulation of its messenger ribonucleic acid, and immunocytochemical localization of the receptor protein. Mol Endocrinol $1988 ; 2$ : 1276-85

20. Chang C, Kokontis J, Liao S. Structural analysis of complementary DNA and amino acid sequences of human and rat androgen receptors. Proc Nall Acad Sci USA $1988 ; 85: 7211-5$.

21. Shan L, Rodriguez MC, Janne OA. Regulation of androgen receptor protein and mRNA concentrations by androgens in rat ventral prostate and seminal vesicles and in human hepatoma cells. Mol Endocrinol 1990 ; $4: 1636-46$.

22. Young CYF, Murthy LR, Prescott JL, el al. Monoclonal antibodies against the androgen receptor : recognition of human and other mammalian androgen receptors. Endocrinology 1988 ; 123 : 601-10.

23. Liao S, Witte D. Auto-immune antiandrogen-receptor antibodies in human serum. Proc Nall Acad Sci USA 1985 ; 82 : 8345-??.

24. Demura T, Kuzumaki N, Oda A, el al. Establishment of monoclonal antibody to human androgen receptor and its clinical application for prostatic cancers. $A m \mathrm{~J}$ Clin Oncol 1988 ; 11 (suppl.) : 523-6.

25. Liao S, Kokontis J, Sai T. Hiipaka A. Androgen receptors : structures, mutations, antibodies and cellular dynamics. J Steroid Biochem 1989 ; 34 : 41-51. cement de nucléosomes permettant à d'autres facteurs de transcription de se fixer à leur tour sur leurs cibles d'ADN. Ce domaine est également capable de se lier à de l'ARN ; (3) 43 acides aminés ; une région variable intermédiaire flexible ; (4) 252 acides aminés ; la région Cterminale qui porte le site de liaison de l'androgène.

L'expression de l'ADNc cloné dans des cosmides a confirmé que la protéine produite présentait tous les caractères spécifiques du récepteur des androgènes : saturabilité et spécificité en particulier.

La séquence complète de l'ADNc a révélé qu'il était composé de 919 acides aminés et que le poids moléculaire était de $90 \mathrm{kDa}$.

L'organisation génique (figure 1) montre huit exons pour un gène de plus de 90 kilobases $(\mathrm{kb})$ :

- le premier exon code pour le domaine $\mathrm{NH}_{2}$-terminal riche en Gly et en Gln. C'est l'exon le plus long (1 586 paires de bases, pb) ;

- les deuxième (152 pb) et troisième (117 pb) exons codent respectivement pour les premier et second doigts de $\mathrm{Zn}^{2}+\mathrm{du}$ domaine de liaison de l'ADN ;

- les cinq exons suivants, d'une taille variant de 131 à 288 pb, codent pour la partie flexible et le domaine de liaison de l'androgène.

Cette organisation génique est commune à la majorité des récepteurs nucléaires. Au total, le récepteur nucléaire des androgènes, comme celui des autres hormones stéroïdes, des hormones thyroïdiennes, de l'acide rétinoïque et de la vitamine $\mathrm{D}$, appartient à la superfamille des récepteurs nucléaires [18] (figure 2). La similitude de structures peptidiques du domaine de liaison à l'hormone explique les possibles interactions des autres récepteurs nucléaires avec des androgènes naturels, des androgènes de synthèse ou des antiandrogènes. C'est cependant au niveau du domaine de liaison à l'ADN que les analogies entre les différents membres de cette famille sont les plus importantes.

L'expression de l'ARNm du récepteur des androgènes par Northern blot montre une bande de 9,6 kb, pour des fibroblastes de territoires sexuellement différenciés, des cellules pros- tatiques ou d'autres cellules androgéno-dépendantes [19]. D'autres équipes ont détecté la présence de trois ARNm. Par ailleurs, il semble exister chez l'animal un rétrocontrôle négatif, par les androgènes, de l'abondance de l'ARNm et de la synthèse du récepteur $[20,21]$ : les quantités d'ARNm et la concentration du récepteur des androgènes augmentent après castration et se normalisent après administration d'androgènes. Une telle régulation, qui vient d'être rapportée dans une lignée d'hépatome humain, reste à démontrer dans les cellules androgéno-dépendantes.

Le développement d'anticorps polyclonaux et monoclonaux contre le récepteur des androgènes représente une approche complémentaire à la fois pour l'analyse de la localisation immuno-histochimique du récepteur des androgènes dans les cellules cibles comme la prostate [22] et la caractérisation du récepteur. Le groupe de Liao [23] a obtenu des anticorps polyclonaux anti-RA en immortalisant des lymphocytes $B$ de sérum de patients porteurs de cancer de la prostate (et synthétisant des autoanticorps anti-RA). L'utilisation de protéine de fusion dans des systèmes bactériens permet l'obtention d'anticorps anti-RA spécifiques d'une région donnée du récepteur. L'utilisation d'anticorps dirigés contre des épitopes particuliers, développés contre des protéines hybrides produites par génie génétique, a permis à Demura et al. [24] de suggérer l'existence de deux types de récepteur des androgènes dont l'un serait spécifique des cellules cibles (fibroblastes de prépuce, cancer de prostate androgénodépendant) et l'autre non.

Mécanisme d'action des androgènes Les androgènes sont impliqués dans la régulation de l'expression de protéines qui participent à l'organisation du phénotype masculin. L'effet majeur des androgènes, comme celui des autres stéroïdes [25] concerne la stimulation de la transcription de gènes hormono-sensibles par les complexes androgènes-RA (A-RA). En fait, in vivo, la localisation initiale du récepteur des androgènes est nucléaire, comme celle des autres récepteurs stéroïdiens à l'exception 
du récepteur des glucocorticoïdes [5]. Le récepteur des androgènes est activé par sa liaison à l'hormone, qui entraîne sa transconformation. Le complexe A-RA acquiert ainsi une forte affinité pour ses sites de liaison à l'ADN, auxquels il va se fixer étroitement, déclenchant les mécanismes de la transcription. Dans la lignée humaine LNCaP, le groupe de Brinkmann a décrit une phosphorylation du récepteur des androgènes après la fixation de l'androgène sur le site de liaison [7]. Contrairement au récepteur de la progestérone, le démasquage, par une protéine de choc thermique HSP90, du domaine de liaison de l'ADN et des sites d'interaction avec les séquences d'ADN [24] n'est pas prouvé pour le récepteur des androgènes (figure 3 ). Un autre rôle de ce complexe A-RA serait de régler la maturation, le transport, la stabilisation et/ou l'utilisation de l'ARN [25].

\section{Étude moléculaire des syndromes de résistance aux androgènes}

Les syndromes de résistance partielle et $a$ fortiori complète aux androgènes associés à un déficit en récepteur pouvaient constituer des situations privilégiées pour la recherche d'une délétion du gène du récepteur des androgènes. Une observation récente de délétion dans le domaine de liaison de l'androgène [26] ainsi que la description de mutations ponctuelles du gène du récepteur des androgènes confirment l'intérêt diagnostique, génétique et fondamental d'une telle démarche.

Étude du gène du récepteur des androgènes : recherche de polymorphisme de longueur des fragments de restriction et de délétions ou de réarrangements

La première approche a consisté en l'étude des fragments de restriction du gène du récepteur des androgènes de 83 patients qui présentaient soit une insensibilité complète aux androgènes $(n=50$, phénotype féminin, RA indétectable par l'analyse des courbes de saturation), soit une insensibilité partielle $(n=33$, masculinisation incomplète, élévation des

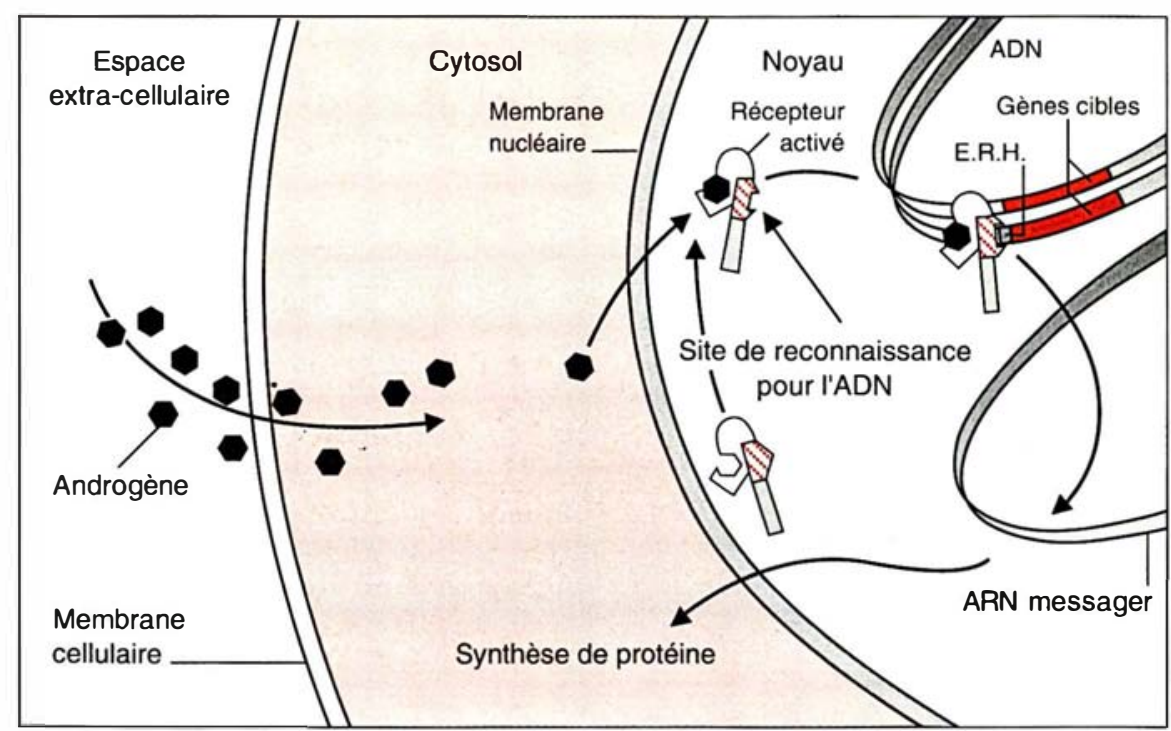

Figure 3. Schéma du mécanisme d'action des androgènes. $E R H=e ́ l e ́-$ ment de réponse hormonale.

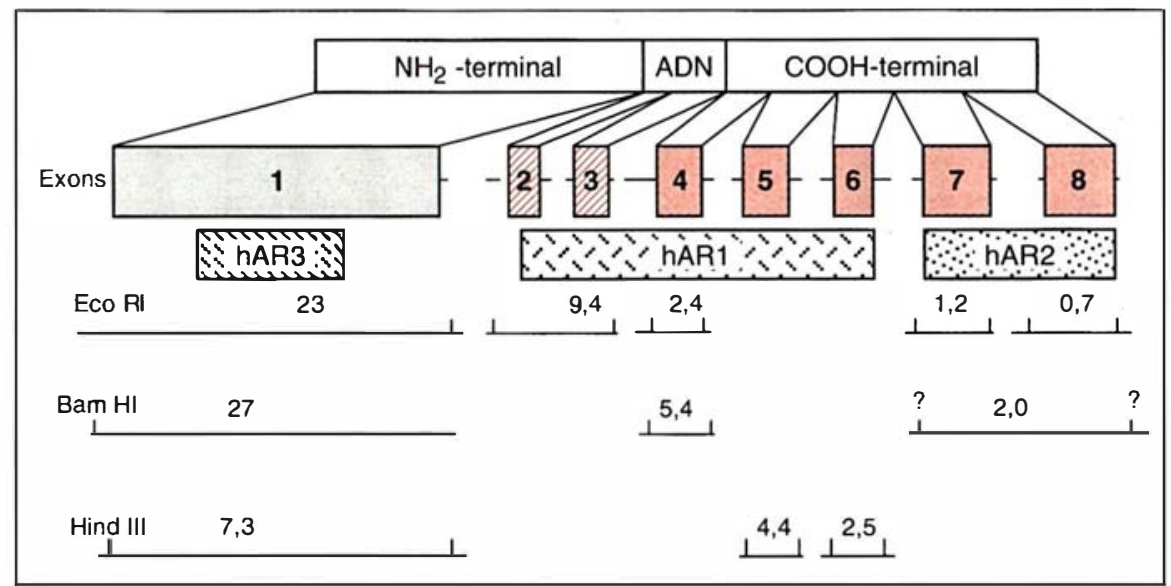

Figure 4. Sondes nucléotidiques et enzymes de restriction utilisées pour I'analyse des fragments de restriction. La taille des fragments est en $k b$.

androgènes circulants et de la $\mathrm{LH}$, $\mathrm{RA}<300 \mathrm{fmol} / \mathrm{mg}$ d'ADN ; au niveau des organes génitaux, $\mathrm{N}=$ $650 \pm 200 \mathrm{fmol} / \mathrm{mg}$ d'ADN). Les $\mathrm{ADN}$ génomiques des patients (et de leur famille dans la plupart des cas) ont été digérés par les enzymes de restriction Eco RI, Bam HI et Hind III et étudiés par Southern blot. Trois sondes nucléotidiques ont été utilisées (figure 4): h AR1 couvrant les exons 2-3-4-5-6; h AR2 couvrant les exons 7-8; h AR3 couvrant la partie médiane de l'exon 1.

L'analyse des fragments de restriction chez ces 83 patients n'a révélé de délétion ni complète ni partielle du gène du récepteur des androgènes. Les délétions partielles que nous avons rapportées avec TaqI [27] dans une famille nécessitent une étude complémentaire. Le caractère exceptionnel de la délétion d'une partie plus ou moins importante du gène $d u$ récepteur des androgènes est attesté par les données récentes de différents groupes. La seule délétion partielle du domaine de liaison au stéroïde a été rapportée par Brown [26] : il s'agit d'une délétion des exons 4, 5, 6,7 et 8 codant pour le domaine de liaison de l'hormone, chez un patient porteur d'une insensibilité complète aux androgènes.

Dans ces conditions, il est légitime de s'interroger sur le bien-fondé d'une investigation longue et coûteuse. En effet, l'analyse moléculaire des syndromes d'insensibilité aux androgènes obéit à une problématique 


\section{RÉFÉRENCES}

26. Brown TR, Lubahn DB, Wilson EM Joseph DR, French ES, Migeon CJ. Deletion of the steroid-binding domain of the human androgen receptor gene in one family with complete androgen insensitivity synrome: evidence for further genetic heterogeneity in this syndrome. Proc Nall Acad Sci USA 1988 ; 85 : 8151-5.

27. Lobaccaro JM, Ktari R, Brown TR, French FS, Roizes G, Sultan Ch. Deletion of the DNA-binding domain of the human AR gene in patients with CAIS. In : Sexual Differentiation: Basic and Clinical Aspects. Montpellier: symposium International, 1989.

28. Lobaccaro JM, Belon Ch, RuizPacheco R, et al. Genetic association of Hind III polymorphism with the androgen receptor gene in partial endrogen insensitivity syndrome. Ann Genet 1991 (sous presse).

29. Marcelli M, Tilley WD, Griffin JE, McPhaul MJ. Molecular basis of androgen resistance in a family affected by a qualitative abnormality of the androgen receptor and responsiveness to high dose androgen therapy. J Clin Invest 1991; 87 : 1413-21

30. Lubahn DB, Brown TR, Simental JA, et al. Sequence of the intron/exon junctions of the coding region of the human androgen receptor gene and identification of a point mutation in a family with complete androgen insensitivity. Proc Nall Acad Sci USA 1989 ; 86 : 9534-8.

31. Trifiro M, Mhatre A, Pinsky L, Kauf man M. Androgen-selective androgen resistance due to a simple point mutation in exon 6 of the X-linked androgen receptor gene. Abstract of The Endocrine Society, 72nd Meeting, 1990 : 93.

32. Marcelli M, Tilley WD, Wilson CM Griffin JE, Wilson JD, McPhaul M. Definition of the human androgen receptor gene permits the identification of mutations that cause androgen resistance: premature termination of the receptor protein at amino acid residue 588 causes complete androgen resistance. Mol Endocrinol 1990 : 4 : 1105-16.

33. Marcelli M, Tilley WD, Wilson CM, Wilson JD, Griffin JE, McPhaul M. A single nucleotide substitution introduces a premature termination codon into the androgen receptor gene of patient with receptor negative androgen resistance. $J$ Clin Invest $1990 ; 85: 1522-8$.

34. Marcelli M, Zoppi S, Grino PB, Griffin JE, Wison JD, McPhaul MJ. A mutation in the DNA-binding domain of the androgen receptor gene causes complete testicular feminisation in a patient with receptor-positive androgen resistance. $J$ Clin Invest 1991; 87 : 1123-6. d'ordre physiopathologique, diagnostique, de conseil génétique et de diagnostic prénatal. L'absence de délétion ne permet pas de répondre à ces différents problèmes. Existe-t-il d'autres éléments qui pourraient les aborder indirectement?

Par l'étude des RFLP (restriction fragments lenght polymorphism), lorsqu'il n'y a pas de délétion importante, on peut espérer différencier les deux chromosomes X maternels dans une famille où l'un des enfants présente une insensibilité aux androgènes. Une étude de la ségrégation chromosomique pourra être envisagée et appliquée aux familles "à risque " pour un diagnostic anténatal (sur trophoblaste). Le seul polymorphisme connu a été rapporté par Brown [9] : polymorphisme Hind III/hAR1 $(6,7$ et/ou 3,5 kb) observé chez $10 \%$ des $\mathrm{X}$ étudiés. Seule la présence de ce site polymorphe à l'état hétérozygote chez la mère permet cette étude différentielle des deux chromosomes $\mathrm{X}$. Nous avons observé ce polymorphisme Hind III chez la mère d'un enfant porteur d'une insensibilité partielle aux androgènes, avec absence de macrodélétions du gène du récepteur des androgènes [28]. Avec la sonde hAR1, la présence des fragments 6,7 et $3,5 \mathrm{~kb}$ chez la mère permet une analyse différentielle de ses deux $\mathrm{X}$, de reconnaître l'X porteur de l'insensibilité partielle aux androgènes. Dans ces conditions, il est possible d'utiliser ce polymorphisme pour envisager le diagnostic prénatal d'insensibilité partielle aux androgènes sur biopsie de trophoblastes, lors d'une future grossesse. Dans une autre famille dont le premier enfant est porteur d'un pseudohermaphrodisme par insensibilité partielle aux androgènes nous avons pu réaliser un diagnostic prénatal d'insensibilité partielle aux androgènes par mise en évidence de l'allèle porteur chez le fœtus.

\section{Étude des produits d'amplification} La seconde approche pour l'étude du gène du récepteur des androgènes est l'amplification enzymatique. La découverte de la Taq polymérase I et le développement de "bains-marie " programmables a simplifié, en temps et en manipulations, les amplifications géniques. Par la technique de
PCR (réaction en chaîne de la polymérase), il est maintenant possible d'amplifier certaines parties du récepteur des androgènes pour une analyse plus fine. Une pareille approche a en effet dé jà démontré son efficacité dans l'analyse moléculaire des syndromes de résistance à la vitamine D.

En matière d'insensibilité aux androgènes, plusieurs types de mutations du gène ont été rapportées (Tableau I).

- Le groupe de Marcelli [29] a décrit, chez un patient présentant une ambiguïté génitale importante, deux anomalies du gène du récepteur des androgènes: une délétion dans l'exon 1 (de l'acide nucléique 369 à 393) entraînant une protéine tronquée de l'acide aminé 69 à 76 et, dans l'exon 5, une mutation $A^{2444} \rightarrow \mathrm{G}$ entraînant un changement Tyr $^{761} \rightarrow$ Cys ; une étude plus poussée pourra différencier les mutations silencieuses de celle(s) responsable(s) de la thermolabilité du récepteur dans cette famille.

- Dans le domaine de liaison de l'androgène, d'autres mutations ont été rapportées : le groupe de French utilisant douze paires d'amorces pour des amplifications de 190 à 900 pb, suivi d'un séquençage systématique de deux clones d'amplification, a mis en évidence une mutation $\mathrm{G} \rightarrow \mathrm{A}$ dans l'exon 7 responsable d'un remplacement $\mathrm{Val} \rightarrow$ Met en position $866 \mathrm{chez}$ un patient dont la concentration en récepteur des androgènes était normale avec une faible affinité de celuici pour l'androgène [30]. Trifiro et al. [31] ont décrit une mutation $\mathrm{G}^{2969} \rightarrow$ A dans l'exon 6 (région hautement conservée) entraînant une modification $\mathrm{Ser}^{813} \rightarrow$ Asn responsable d'une insensibilité partielle aux androgènes dans deux familles.

- Dans l'exon 3, le groupe de Marcelli a décrit deux mutations : la première, $\mathrm{T}^{1924} \rightarrow \mathrm{A}$, entraîne une modification Lys ${ }^{588} \rightarrow$ Stop responsable d'une protéine tronquée n'ayant aucune activité de liaison à l'ADN [32] (une mutation identique a été rapportée par ce même groupe [33]). La seconde mutation ponctuelle, $\mathrm{G}^{2006} \rightarrow \mathrm{C}$, provoque le remplacement d'une Arg en Pro sur l'acide aminé 615 au niveau du second doigt de gant dans le domaine 

dont le comportement physicochimique du récepteur des androgènes était normal (le rôle de la mutation a été démontré directement par mutagenèse dirigée) [34].

- Enfin, Sai décrit, dans une forme familiale d'ICA, une mutation $\mathrm{G} \rightarrow$ A dans l'exon 4 entraînant une modification $\operatorname{Trp}^{717} \rightarrow$ Stop, responsable d'une capacité de liaison très basse. Paradoxalement, dans la lignée cellulaire $\mathrm{LNCaP}$ où le récepteur des androgènes présente une très haute affinité pour tous les stéroïdes, Veldscholte décrit une mutation dans le domaine de liaison de l'androgène. Cette mutation rendrait compte de l'absence de spécificité du récepteur nucléaire [35].

Notre groupe participe activement à la recherche de délétions et de mutations du gène du récepteur des androgènes [36]. de liaison de l'ADN d'un patient

Dans la mesure où deux mutations avaient été décrites dans le domaine de liaison à l'androgène, nous avons décidé d'amplifier les exons 6,7 et 8 des 83 patients (50 ICA + 33 IPA) par PCR à l'aide d'amorces couvrant les sites d'épissage en 5' et en 3' de chaque exon. L'étude de la séquence des produits d'amplification est en cours par l'utilisation de techniques puissantes associées à la PCR :

- l'électrophorèse sur gel d'acrylamide avec gradient de dénaturation (DGGE) : la méthode repose sur la différence de propriété de migration en condition dénaturante de deux fragments d'ADN de même taille mais de compositions différentes;

- l'étude du polymorphisme de conformation des ADN simple brin (SSCP): des fragments "simple brin " d'ADN de même taille, ayant subi une dénaturation, vont prendre une conformation dans l'espace dif-

Tableau

\section{MUTATIONS OBSERVÉES ET CONSÉQUENCES CLINIQUES}

\begin{tabular}{|c|c|c|c|c|}
\hline $\begin{array}{r}\text { Mu } \\
\text { nucléotides }\end{array}$ & $\begin{array}{l}\text { tations } \\
\qquad \text { codons }\end{array}$ & Anomalie protéique & Symptomatologie & Références \\
\hline $\begin{array}{l}\text { exon } 1 \\
\text { del 369-393 }\end{array}$ & del 69-76 & Protéine tronquée & $\begin{array}{l}\text { Ambiguïté génitale } \\
\text { importante }\end{array}$ & [29] \\
\hline $\begin{array}{l}\text { exon } 3 \\
\text { T1924 } \rightarrow A\end{array}$ & Lys ${ }^{588} \rightarrow$ Stop & $\begin{array}{c}\text { Protéine tronquée } \\
\text { sans capacité } \\
\text { de liaison }\end{array}$ & ICA & [32] \\
\hline $\begin{array}{l}\text { exon } 3 \\
G^{2006} \rightarrow C\end{array}$ & $\operatorname{Arg} 615 \rightarrow$ Pro & $\begin{array}{c}\text { Capacité } \\
\text { de liaison normale } \\
\text { pas de liaison à } \\
\text { I'ADN }\end{array}$ & ICA & [34] \\
\hline $\begin{array}{l}\text { exon } 4 \\
G \rightarrow A\end{array}$ & Trp $717 \rightarrow$ Stop & $\begin{array}{l}\text { Protéine tronquée } \\
\text { ayant une capacité } \\
\text { de liaison très basse }\end{array}$ & ICA & - \\
\hline $\begin{array}{l}\text { exon } 5 \\
A^{2444} \rightarrow G\end{array}$ & Tyr $761 \rightarrow$ Cys & $?$ & $\begin{array}{l}\text { Ambiguité génitale } \\
\text { importante }\end{array}$ & [29] \\
\hline $\begin{array}{l}\text { exon } 6 \\
C \rightarrow T\end{array}$ & $\operatorname{Arg} 774 \rightarrow$ Cys & $\begin{array}{l}\text { Récepteur } \\
\text { indétectable }\end{array}$ & ICA & [37] \\
\hline $\begin{array}{l}\text { exon } 6 \\
G^{2969} \rightarrow A\end{array}$ & $\operatorname{Ser} 813 \rightarrow$ Asn & $\begin{array}{l}\text { Diminution } \\
\text { de l'affinité }\end{array}$ & IPA & [31] \\
\hline $\begin{array}{l}\text { exon } 7 \\
G \rightarrow A\end{array}$ & Arg $831 \rightarrow$ Glu & $\begin{array}{l}\text { Récepteur } \\
\text { indétectable }\end{array}$ & ICA & [37] \\
\hline $\begin{array}{l}\text { exon } 7 \\
G \rightarrow A\end{array}$ & Val $866 \rightarrow$ Met & $\begin{array}{l}\text { Diminution } \\
\text { de l'affinité }\end{array}$ & ICA & [30] \\
\hline
\end{tabular}

IPA : insensibilité partielle aux androgènes; ICA : insensibilité complète aux androgènes; del : délétion.

$\mathrm{m} / \mathrm{s} n^{\circ} 7$, vol. 7 , septembre 91 férente et ainsi migrer différemment selon leur composition en acides nucléiques.

La sensibilité de ces techniques peut ainsi permettre de mettre en évidence des "hétérogénéités" dans les différentes amplifications et détecter par séquençage des mutations ponctuelles, associées ou non, à la résistance aux androgènes. Par la méthode de DGGE, Brown [37] a décrit chez deux patients présentant une insensibilité complète aux androgènes, associée à des récepteurs indétectables, une mutation $\operatorname{Arg}^{774} \rightarrow$ Cys et une mutation $\operatorname{Arg}^{831} \rightarrow$ Glu dans le domaine de liaison de l'hormone.

\section{Étude de l'ARNm}

La troisième approche semble être l'étude de l'ARN messager. Si le Northern blot est la technique usuelle (étude de l'abondance relative de l'ARNm pour évaluer une diminution de la transcription du gène ou une augmentation dans les cas d'hypersensibilité aux androgènes), on peut également envisager l'amplification de l'ARNm pour l'étude de ses sites d'épissage en cas de protéines tronquées. Cette investigation est développée dans notre équipe.

\section{Utilisation d'anticorps anti-RA}

Le développement récent d'anticorps polyclonaux et monoclonaux constitue enfin la quatrième approche de l'étude des syndromes de résistance aux androgènes. $A$ partir de la séquence protéique, déduite de la séquence de l'ARNm, il est possible d'envisager la synthèse d'anticorps dirigés contre des épitopes du récepteur des androgènes pour une analyse topographique dans les cellules cibles comme les cellules prostatiques. On peut également envisager l'étude d'une région particulière du récepteur et de déduire son interaction avec les autres domaines du récepteur des androgènes.

Le développement d'anticorps monoclonaux contre le récepteur des androgènes représente un acquis technologique remarquable dont les applications immédiates sont représentées par:

- le développement de dosage immuno-enzymatique du récepteur des androgènes ;

- la localisation du récepteur des 
androgènes dans des populations cellulaires différentes ;

- les études de variation de concentration du récepteur des androgènes dans un même tissu (en fonction de l'âge ou du niveau d'androgènes circulants, par exemple).

L'ensemble de ces résultats permet de proposer pour l'avenir un schéma concernant l'analyse du gène codant pour le récepteur des androgènes dans les syndromes de résistance aux androgènes, caractéristiques, rappelons-le, par leur polymorphisme clinique [38] et leur hétérogénéité biochimique [39] et génétique [38] : (1) évaluation de la capacité de liaison du récepteur des androgènes sur fibroblastes génitaux par les techniques habituelles de liaison et utilisation d'anticorps pour évaluer la concentration en protéine ; (2) comparaison des cartes de restriction obtenues à partir de l'ADN génomique (ou des fibroblastes) du patient et de sa famille ; (3) étude de l'expression du gène par analyse de(s) l'ARNm ; (4) amplification par PCR du gène du récepteur des androgènes et étude des produits d'amplification par DGGE, SSCP, ... ; (5) séquençage des produits d'amplification lorsqu'une anomalie est détectée ; (6) criblage des récepteurs par des anticorps dirigés contre des épitopes mutés connus.

\section{Conclusion}

Les progrès considérables accomplis en deux ans dans le domaine de la biologie moléculaire du RA ont permis de mettre à notre disposition des outils remarquables : cartes de restriction de l'ADN génomique, PCR, séquences, expression du récepteur, anticorps anti-récepteurs...

Ces outils nous aideront, dans un avenir très proche, à répondre aux questions d'ordre diagnostique et physiopathologique que pose la prise en charge des enfants porteurs de syndrome d'insensibilité aux androgènes

\section{TIRÉS A PART}

C. Sultan.

\section{Summary}

Molecular genetics of androgen insensitivity syndromes

Androgens act on sex differentiation and male phenotype development through a receptor mediated mechanism. In 46XY individuals, $\mathrm{X}$ chromosome-linked androgen insensitivity results in a spectrum of developmental abnormalitics ranging from a complete external female phenotype to partially masculinized external genitalia. Complementary DNA of the androgen nuclear receptor (AR) has been recently cloned and sequenced. The development of $\mathrm{cDNA}$ probes gave the opportunity to study DNA restriction fragments of patients with androgen insensitivity syndrome (AIS). Using cDNA fragments containing the DNA binding domain, the steroid binding domain and a portion of the N-terminal domain respectively, most authors agree that a complete deletion is rarely observed. After enzymatic amplification (along with denaturing gradient gel electrophoreses and single strand conformational polymorphisms) and sequencing of the androgen binding domain, point mutations have been reported in a few cases. Molecular biology has thus opened a new field of investigations of AIS by studying restriction fragment length polymorphisms, mRNA expression, enzymatic amplifications and sequencing. These new tools together with anti-receptor-antibodies will allow to study correlations between structure/function of the AR and also between structure of the AR gene and phenotype in patients with male pseudohermaphroditism due to end-organ resistance.

\section{RÉFÉRENCES}

35. Veldscholte J, Ris-Stalpers C, Kuiper GGJM, et al. A mutation in the ligand binding domain of the androgen receptor of human LNCaP cells affects steroid binding characteristics and response to antiandrogens. Biochem Biophys Res Commun 1990 ; 173 : 534-40.

36. Sultan Ch, Belon Ch, Ktari R, et al. Molecular analysis of androgen receptor gene in androgen insensitivity syndromes : a french collaborative study. Hormon Res $1990 ; 33: 3-10$.

37. Brown TR, Lubahn DB, Wilson EM, French FS, Migeon CJ, Corden JL. Functionnal characterization of naturally occurring mutant androgen receptors from subjects with complete androgen insensitivity. Mol Endocrinol 1990 ; 4 : 1759-72.

38. Pinsky L, Kaufman M. Genetics of steroid receptors and their disorders. Adv Hum Genet 1987 ; 16 : 299-472.

39. Sultan $\mathrm{Ch}$. Androgen receptors and partial androgen insensitivity in male pseudohermaphroditism. Ann Genet 1986 ; 29: 5-10.

\section{Remerciements}

Ce travail a été réalisé avec le soutien financier de l'Inserm. Nous remercions les professeurs et docteurs Battin, Bernasconi, Bianchi, Bost, Boucekkine, Bozzola, Cacciari, Cavallo, Chaabouni, Chaussain, Conte Devolx, Freysz, Hachicha, Hedon, Heinrichs, Job, Josso, Kurtz, Larget-Piet, Lecomte, Limal, Magnin, Malpuech, Mariani, Moraine, Noir, Nivelon, Pugeat, Ranke, Rochiccioli, Schonberg, Tourniaire, Toublanc, Vanderschueren et Vassart de nous avoir adressé les fibroblastes de leurs patients. La collaboration des $\operatorname{Pr}$ F. S. French, D. B. Lubahn et E. M. Wilson (University School of Medicine of North Carolina, Chapel Hill) et T. R. Brown (The Johns Hopkins Hospital, Baltimore) a été indispensable pour l'acquisition des sondes ADNc. Nous remercions Ch. Belon, R. Moustarih et $\mathrm{R}$. Medlej pour leur participation à la réalisation de ce travail. Nous remercions également le $\operatorname{Pr} G$. Lefranc (USTL), le Dr G. Roizes (Inserm U. 249), le Dr J.-C. Nicolas (Inserm U. 58) et le Dr Ph. Berta (Inserm U. 249) pour leurs conseils au cours de la réalisation de ce travail. 